\title{
E-Business Education: A Phenomenographic Study of Online Engagement among Accounting, Finance and International Business Students
}

\author{
Nattavud Pimpa \\ School of Management, Royal Melbourne Institute of Technology, RMIT University, Melbourne, Australia. \\ E-mail: Nattavud.pimpa@rmit.edu.au
}

Received September $15^{\text {th }}, 2010$; revised October $21^{\text {st }}, 2010$; accepted November $23^{\text {rd }}, 2010$.

\begin{abstract}
This paper examines online engagement in the business learning context among international and local students in Australia. Online engagement among business students and lecturers has long been criticized as the key problems in adopting online materials and methods in business education. In examining factors affecting online engagement in business education, the data was collected from undergraduate students in finance, accounting and international business undergraduate students. Moreover, learning and teaching techniques that enhance the quality of online engagement were also investigated in this study. Key factors include the nature of the course, technical aspects from the institutions and cultural backgrounds from the students. This study also finds roles of key stakeholders in business education such as lecturers, technicians and policy makers contributing to the level of online engagement among business students.
\end{abstract}

Keywords: Business Education, Online Engagement, International Education

\section{Introduction}

One important facet of globalisation is technology development. Advancement in technology contributes significantly to the new ways of learning and teaching in all sciences including business studies. Like other disciplines, the implementation of online element in the business education has been one of the most critical aspects worldwide. Due to its effectiveness in promoting flexibility in learning, most universities and business schools attempt to improve the synergism of electronic aspects into their business curriculum. The development of online system for business education has improved the way lecturers construct the pedagogy for business courses. It also improves student's learning experiences [1].

Previous studies discussed the benefits of using online system in teaching and learning in business, economics, and management [2]. At the same time, many commentators argue that the technologisation of education marks a profound change in teaching and learning resulting in a "pedagogical challenges and technology" [3,4], "the transformation of tertiary pedagogy in the context of communications technologies' [5] and learning culture [4] in the local and global business education context. In terms of the fundamental benefits of online learning in the business courses, online learning systems provide higher education institutions with a 'platform' and 'space' for a macro-scale implementation for instructivist pedagogy $[6,7]$.

In the context of learning and teaching in international business, however, researchers have proposed a number of problems and challenges when using electronic forms of education. Previous research study by Raelin and Schemerhom (1994) claims that for online business courses to be effective, faculty and the administration need to integrate program planning, monitoring, management, and resource allocation and careful selection of learning materials. They also need to offer students pre-entry guidance, personal communication and feedback. Identification of the importance of these factors lends strong support to the belief among online educators that distance learning courses that are offered online are not a cheap or discounted method of delivery, if the courses are to be established and delivered properly [8].

The literature in the area of business education identifies the key objectives and benefits of adopting online approach in business education. Lewandowski [9] ex- 
pressed that online approach in business education complement traditional business education by employing a learning platform. It may help in self-evaluation, critical thinking and knowledge sharing among the members of learning community. Ledru (2002) also cited that online learning immerse the learners in technological and business domains. Thus, students are prepared to the world of work. They will master the technology prior to the graduation. Moreover, online system also helps students to maintain regular communication and contacts with their teachers and peers wherever they are in the world [10]. A good example of this benefit is mentioned as "Online business education can enhance further education programs in order to capitalize on the distance learning markets for executive managers, who are mobile, demanding, and not very free to access education" [3]. It can be claimed that the body of literature supports the benefits of online education in business learning.

In terms of factor affecting online learning, previous studies identified four categories that may be potential problems in business education. They are: institutional or organisational, technological, pedagogical and cultural. Institutional issues and their interaction with technology can have a profound effect on culturally diverse students. Conole [11] and Hannon and D'Netto [12] reported issues such as institutional support for online education, communication between students and institutions and guidance from the institution can promote a strong level of online engagement by students. As online learning in business involves a number of activities, people, and processes, it is important for universities and lecturers not to see it as "culture-neutral". Lecturers should be concerned with how cultural differences are managed in virtual learning. There are dangers in simply transferring traditional face-to-face learning methods to an online system. Previous studies make extensive reference to the access, speed, system, and clarity of information and communication technology for the promotion of students' engagement in online education [12]. Finally, cultural factors such as the students' linguistic background, approach to learning, and communication style also play a pivotal role in students' readiness and willingness to engage in online learning.

Given the abovementioned issues, this paper aims to identify factors that impact on engagement with and the effectiveness of, online education among international business students. The outcomes from this project will help educators and researchers in learning and teaching online for international business program to better understand the issues of diversity underpinning students' experience in online education and training. This understanding will provide long-term benefit for higher educa- tion institutions that offer international business program to student from diverse backgrounds.

\section{Phenomenographic Study: The Methodology}

The methodology used in carrying out this research was phenomenography, which aims to understand the various ways in which different people experience, perceive or understand the same phenomenon [13]. Phemonenography is a qualitative research approach in which the interview is the most important and significant research method. The outcome of phenomenographic research is therefore a list, or description, of the qualitative variation in the ways the sample participants experience, understand, perceive or conceptualise an object of study, a concept or an activity. To achieve this objective, qualitatively, semi-structured individual interviews were used to probe the stages involved in students' conceptual development and their approaches to problem solving.

This study adopted phenomenographic because this approach helps develop a descriptive framework based on the two elements of meaning and structure. Meaning is represented in categories of description that regroup logically the views of the participants, simultaneously contrasting differences and clustering similarities. Structure is represented within each category and in an outcome space that indicates the relationships between the categories. The structural elements of each category and the outcome space are typically most useful for developing understanding of the phenomenon investigated [4].

The participants in this study include 27 undergraduate students (6 accounting, 8 finance and 13 international business students) in the bachelor of business degree programme at one University of technology in Australia. Snowball technique was used to recruit the participants in this study. All of them are final year students in the bachelor of business program. The participants are local, international, and exchange students. It was expected by the researcher that their cultural and learning backgrounds will add to the diverse life stories of the participants. This aspect will enhance a key concept of phenomenology approach.

Personal interviews were conducted by the researcher at the main campus of the university. All participants in this study volunteered to participate in the study because they would like to contribute to the development of online learning system of the university.

\section{Data Analysis}

The interviews were transcribed verbatim from the audio-recorder. In analysing the data, qualitatively distinct categories were identified that described the students' approaches to online engagement. Transcripts of the stu- 
dents' interviews were examined independently by the researcher, looking for both similarities and differences among them, selecting significant statements and comparing these statements in order to find cases of variation or agreement and thus grouping them accordingly.

Through the data analysis process, using only a sample of the interview transcripts, initial categories were developed that described students' approaches to problem-solving and stages of conceptual development. Once this initial categorisation was complete, the researcher met with other research fellows to discuss their categories and their interpretation of the answers. The categories were then revised until the researcher reached a consensus about the final set of categories. With these categories in mind the interview transcripts were reexamined, to determine if the categories were sufficiently descriptive and indicative of the data. This iterative data analysis procedure is consistent with the phenomenographic approach.

\section{Results}

The analysis of the data revealed the personal backgrounds, experiences, and levels of engagement in online accounting, finance and international business education vary between individual students. The following themes indicate a conceptual change path undergone by most participants in this study. The findings relate to the following five themes of conceptions of online engagement in international business education:

\subsection{The Nature of the Business Courses}

All participants in this study admitted that they were familiar with (and saw the real values of) online engagement. This point is the key factors that support international management students to engage in the online more often than accounting and finance students. The fact that most courses are practical helps students to engage frequently with their academic community. In this situation, each individual participant reflected upon their experiences as an observer of the global community (PA-1). Stories related international business (such as current affairs, daily conversation, global products or services and other daily live activities) were incorporated into online conversation or case analysis among business students in this study. This aspect is perceived as touchable (PA-2), intellectually rigorous (PA-3), stimulating (PA-3), and connected to the competitive forces that determine business decision making (PA-4). Each participant was asked to identify his/her most interesting experience in international business online engagement. Most students felt they could relate (PA-5) well to both theories and practices, such as international modes of entry and the products or services that are related to their daily lives (i.e., luxury apparel, airlines, hotels, computer and electronic appliances, and souvenirs). They admitted that most lecturers would add to practical experiences in the lectures, and encourage students to discuss (PA-2) each point of learning in the online forum. Face-to-face lecture that encourages lively discussions seems to provide an avenue for further discussion online and facilitate the process of student learning during the course.

A number of participants describe the nature of finance course as time-consuming in study in the class and online system, having several foci in one course. The problem that most students in this study discussed was the fact that most financial courses encourage the use of various ' $\mathrm{fi}$ nancial models' and students feel that finance is a collection of models, decision-making and rules, and lacking in interlinks (PA-6) among the models and theories. The use of online discussion among students and teaching staff helps students to spend more time on thinking about the links between financial models and theories and better understand the nature of the course.

The results also show that the nature of accounting course is critical. The use of online platform to discuss process and complication in auditing, ethics and techniques in cash-flow methods is appropriate for the nature of students. Most accounting students in this study admitted that learning about taxation, international finance and management accounting requires the combination (PA-7) of online and face-to-face modes of learning and teaching.

The method of learning and teaching (in both face-toface and online classes), which encourages the use of industrial experiences and case studies of international organisations, was frequently mentioned by the participants of this study. When real-life examples are used in discussions, the participants expressed they feel more 'knowledgeable' and stimulated by way of online discussion. The practical examples from industry could foster lively online discussion in various international business topics. One example raised a few times by participants in this study is of globalisation and global consumers. The theoretical concepts of globalisation are discussed in almost all international business classes and one of the obvious effects is the transformation of global consumers. All participants mentioned their contributions to the forum by using their personal experiences with global brands (i.e., ING, Qantas, Samsung), global products (iPad, Kindle, teeth whitening gel), global services (airlines, education, tourism and hospitality, medical). The references of the 'global factors' promotes not only lively online participation among local Australian students, but also the conversations extending hard theo- 
ries to touchable topics of among students from different backgrounds and among students and lecturers.

\subsection{Technical Aspects in Online Business Education}

Technical aspects that all participants in this study raised include the combinations of problems from both institutional and lecturer factors. Participants in this study felt, for the most part, the online environment consists of a multiplicity of tools, but is generally poor in design and guidance (TAI-1). There is often no clear indication (TAI-1) of how learning activities and information resources (content) are interwoven (TAI-2). Their stories of technical and institutional aspects express more negative than positive experiences. All participants each reflected back to their first year in the program when they enrolled in courses such as foundation to international business, micro economics, or foreign languages. Some of them were required to engage in various online teaching and learning activities. Most participants articulated that a lack in proper training (TAI-1) for new students of both local and international students) significantly undermined the perceived quality of the course and their levels of engagement in the online forums. One participant in this study expressed that institutional policy 'forces' (TAI-3) their lecturers to design online teaching and learning activities, rather than the strong intention to improve students' learning experiences.

The findings also showed that lecturers who have the capacity to respond effectively to differences in learner needs, curriculum or situation, are perceived as encouragers of students to engage in online learning. All participants in this study admitted that when the lecturers are able to draw selectively from an extensive repertoire of resources and strategies (in order to motivate learners and to encourage active learning); they are enthusiastic to engage in an online forum. This finding concurs with those from previous studies, reporting that students attending a class with a lecturer who has a positive attitude towards online education, and who promotes technology in teaching, are likely to experience more positive learning outcomes.

In terms of the positive aspects of technical and institutional supports, all participants reflected upon the 'quick and broad access' (TAI-4) and 'varieties' and 'quality' in services (TAI-5) provided to them throughout their education. The quick access to the system, quality of the interface, and access to the database and other forms of online resources support students' online engagement in the sense that they are not impeded by the technical boundaries of the learning experiences. The well-designed international business course should syn- chronize with "various means of navigation." The system that provides a variety of resources can facilitate the use of industrial and global examples in online discussions.

The last aspect of this conception is the informal interaction among the learning community. All participants reflected upon their experiences on the similar accounting, finance and international business courses that encourage informal interaction among their group members. Institutional policies that support this informal connectivity and interaction (TAI-6) include "wi-fi hot spots" throughout the university, the combination of student online and face-to-face discussion groups, and the use of e-international media in the form of entertainment or current affairs to discuss the content (in particular in foreign language classes).

\subsection{Cultural Factors in Business Education}

The interaction of different cultures may be a challenge and could create difficulties in the learning and engaging process in the context of business education. Hence there are several factors business educators must be aware of before conducting business education among students of diverse backgrounds. Various aspects of culture, such as Australian and non-Australian concepts of learning, students views to the world, perception of space in learning from Australian and non-Australian contexts, were revealed by the participants in this study.

Demographic backgrounds and experiences of the participants in this study were frequently mentioned as a key factor enhancing their online engagement behaviour in accounting, finance and international business course. Most participants in this study are diverse in both cultural and academic backgrounds. Students from Chinese, Korean, Indonesian, and Vietnamese backgrounds reflected upon their extreme active participation and engagement in various forms of online teaching and learning in courses such as international management, global financial management, accounting for SMEs, global marketing, and international human resources management. Students who speak English as a second language confirmed that the use of online resources (such as course materials, journal articles, discussion board, and wiki) is extremely helpful for their learning experiences and thinking process. In most international business courses, this cohort prefers having a combination of face-to-face and online teaching and learning because it creates 'collaboration' (SB-1), 'harmony' (SB-2), and a 'challenging' (SB-3) ambiance in the online forum. Furthermore the concept of being formal or informal (SB-2) in online engagement, in language and style, was frequently mentioned by the participants in this study.

Most of finance and accounting students in this study 
are international students from East Asian nations (China, South Korea and Japan). They agreed that the culture of 'collectivism' plays a pivotal role in promoting online engagements among them. They feel more comfortable to discuss some serious issues such as taxation, ethics or international financial systems in the online with their friends because they feel more 'safe' in the sense of not loosing their faces in the public arena.

Furthermore, how students engage in learning is also influenced by personal experiences within particular cultural contexts. The findings from this study reveal that student reactions to the social constructivist learning environments differ, depending on not only their prior experiences, but also according to the distinct communication (SB-4) norms across cultures. Phrases such as 'being polite in your writing', 'not being too expressive or emotional', 'writing with a proper style', and 'challenging your team in the discussion' were mentioned when all participants reflected upon the problems in online engagement. In this regard, cultural aspects therefore flavour students' expectations of the online learning environment. In this study, Australian and international groups share similarities in being proactive in the online teaching and learning, relying upon their lecturers at the beginning of the class and subsequently becoming more autonomous in online contribution, and tending to be more casual in language but focussed in content for online teaching and learning.

The references to local and international cultural background are another aspect that the participants mentioned frequently in this study. All participants feel that it is more appropriate to refer more to Australian rather than nonAustralian contexts, although the nature of the course is international. Two Anglo-Australian students and one Asian-Australian student in this study expressed their needs to know more about non-Australian products, brands, consumers, management styles, and cultural references. However, all international and exchange students in this study mentioned how awkward it could be to mention their hometown brands, products, or case studies. They felt the disconnection of cultural references of Australia and their home countries may cause confusion in the discussion forum. This is a typical example of cultural mismatch in students' expectation.

\section{Implications}

This study identifies three key aspects that affect the level of online engagements among business students from three disciplines. There are a number of similarities that promote the high level of engagement among business students. Institutional factors seem to play a pivotal role in this context. The nature of the course, the links between academic and personal backgrounds and the institutional supports seem to foster the quality of online engagement among the participants in this study. This study also indicates online education can be a powerful tool in accounting, finance and international business education. This tool has the potential both to support effective education programmes and to expose students to the implications of online networks. It is evident, though, that lecturers need to upgrade their skills in order to keep in touch with the technological, pedagogical, and cultural developments that are taking place. As this study illustrates, the online and traditional classroom teaching methods should be seen as an extra dimension in education which can facilitate the lecturer's learning objectives while benefiting the students. In this study, accounting students seem to be more familiar with the use of online technology in their learning. One of the reasons is personal familiarity and technical training and awareness raising from the business schools or University. Thus, it is strongly suggested to all universities to create the mindset of electronic resource among their students from the beginning of their university's life.

The combination of both individual and group-based online activities is encouraged if we need to stimulate students to be more active. Since the practical aspect of international business course is one of the key factors encouraging students to be more proactive in the online forum, online group work should be encouraged. Working in groups of two or three students is an active learning technique frequently used in many face-to-face classes; it can also be successfully used in online courses. If the students are expected to work in online teams, students should be informed of other team member's details, access to and technological aspects of the online forum, and the expectations of the lecturer. Furthermore, make sure that the expectation for the international business online work is to allow individual ideas, perspectives, and experiences to be heard and collectively considered by the team. The idea of agreeing to disagree will be learnt through these experiences.

The trends of digitization and technology in business in education seem inevitable. It is, thus, crucial for policy makers and business educators to understand the nature of the curriculum, new technology, learning environments and the nature of students. Such understanding will contribute to the quality and effectiveness in implementing technology in business education in both local and international levels.

\section{Acknowledgements}

This project is funded by the Accounting and Finance Association of Australia and New Zealand (AFAANZ) 
through the 2008 AFAANZ research grant scheme.

\section{REFERENCES}

[1] N. Pimpa, "Transnational MBA Programmes in Thailand," International Journal of Management in Education, Vol. 2, No. 4, 2008, pp. 401-418.

[2] A. Ettinger, V. Holton and E. Blass, "E-Learner Experiences: A Lesson on In-House Branding," Industrial \& Commercial Training, Vol. 38, No. 1, 2006, pp. 6-33.

[3] P. Daly, "The Pedagogical Challenges Facing French Business Schools in the Implementation of E-LEARNINg Initiatives," The International Journal of Learning and Teaching in Higher Education, Vol. 18, No. 2, 2006, pp. 89-96.

[4] N. Pimpa, "Learning Problems in Transnational Business Education and Training: The Case of the Master of Business Administration in Thailand," International Journal of Training and Development, Vol. 13, No. 4, 2009, pp. 262-279.

[5] C. McLoughlin, "Crossing Boundaries: Curriculum and Teaching Implications of Culturally Inclusive," 2001. www.aare.edu.au/01 pap/mcl01720.htm

[6] P. Goodyear, "Educational Design and Networked Learning: Patterns, Pattern Languages and Design Practice," Australasian Journal of Educational Technology, Vol. 21, No. 1, 2005, pp. 82-101.
[7] P. Goodyear and C. Jones, "Implicit Theories of Learning and Change: Their Role in the Development of E-Learning Environments in Higher Education," In: S. Naidu, Eds., Learning and Teaching with Technology: Principles and Practice, Routledge Farmer, London and New York, 2003, pp. 29-41.

[8] J. Raelin and J. Schemerhorn, "A New Paradigm for Advanced Management Education - How Knowledge Merges with Experience," Management Learning, Vol. 25, No. 2, 1994, pp. 195-200.

[9] J. Lewandownski, "Les Nouvelles Facons de Former: Le e-Learning Enjeux et Outils," Editions D'Organisation, Paris, 2003.

[10] M. Ledru, "Le E-Learning, Projet D'Entreprise, Une Approache Strategique du Processus Competences," RueilMalmaison, Editions Liaisons, France, 2002.

[11] G. Conole, "E-Learning: the Hype and the Reality," Journal of Interactive Media in Education, Vol. 12, No. 11, 2004, pp. 11-25.

[12] J. Hannon and B. D'Netto, "Cultural Diversity Online: Student Engagement with Learning Technologies," International Journal of Educational Management, Vol. 21, No. 5, 2007, pp. 418-432.

[13] M. Wihlborg, "Student Nurses' Conceptions of Internationalism in General and as an Essential Part of Swedish Nurses' Education," Higher Education Research and Development, Vol. 23, No. 4, 2004, pp. 433-453. 